удК 665.652.4: 542.973

DOI: $10.15372 / \mathrm{KhUR} 20150602$

\title{
Система $\mathrm{SO}_{4}^{2-} / \mathrm{ZrO}_{2}-\mathrm{Al}_{2} \mathrm{O}_{3}$ как катализатор алкилирования изобутана бутенами
}

\author{
Е. Д. ФЕДОРОВА ${ }^{1}$, Е. А. БУЛУЧЕВСКИЙ ${ }^{1,2}$, А. В. ЛАВРЕНОВ ${ }^{1}$, М. О. КАЗАКОВ ${ }^{1}$, Н. Н. ЛЕОНТЬЕВА ${ }^{1}$, А. Б. АРБУЗОВ ${ }^{1}$ \\ ${ }^{1}$ Институт проблем переработки углеводородов Сибирского отделения РАН, \\ ул. Нефтезаводская, 54, Омск 644040 (Россия) \\ E-mail: jane@ihcp.ru

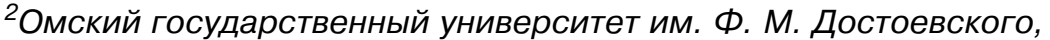 \\ проспект Мира, 55а, Омск 644077 (Россия)
}

\begin{abstract}
Аннотация
Изучено влияние модифицирования сульфатированного диоксида циркония добавками оксида алюминия на его текстуру, фазовый состав, кислотность и каталитические свойства в процессе алкилирования изобутана бутенами. Показано, что наилучшими каталитическими свойствами обладает образец $\mathrm{SO}_{4}^{2-}-\mathrm{ZrO}_{2}-\mathrm{Al}_{2} \mathrm{O}_{3}$ с содержанием оксида алюминия 20 мас. \%, прокаленный при температуре $650{ }^{\circ} \mathrm{C}$.
\end{abstract}

Ключевые слова: алкилирование изобутана бутенами, сульфатированный диоксид циркония, оксид алюминия

\section{ВВЕДЕНИЕ}

Алкилат-бензин - один из наиболее востребованных сегодня типов сырья для производства товарных автомобильных бензинов [1]. Благодаря высокому содержанию триметилпентанов (ТМП), он характеризуется высоким октановым числом, низкой чувствительностью к режимам работы двигателя, не содержит непредельных и ароматических углеводородов, а также сероорганических соединений. Однако, несмотря на очевидные достоинства, доля алкилата в бензиновом фонде России в настоящее время не превышает $10 \%$ [2]. Это обусловлено известными недостатками традиционных технологий алкилирования изобутана бутенами с использованием в качестве катализаторов серной и фртористоводородной кислот. Основные недостатки процесса на данных системах: токсичность, коррозионная активность и высокий удельный расход катализаторов, а также сложность разделения катализаторно-продуктовой смеси, необходи- мость утилизации отходов - кислого гудрона и орторсодержащих соединений [3].

Основное направление совершенствования технологии производства алкилбензина связано с разработкой твердых кислотных катализаторов. В качестве одного из перспективных твердых катализаторов алкилирования рассматривается сульфатированный диоксид циркония (SZ) [4-6]. Сульфатированный диоксид циркония обладает суперкислотными свойствами. Это позволяет проводить процесс алкилирования в мягких условиях $\left(40{ }^{\circ} \mathrm{C}\right.$ и ниже), но сопряжено с протеканием побочных реакций крекинга и переноса водорода, что значительно снижает селективность процесса и стабильность катализатора. Также известно, что кислотные и каталитические свойства SZ можно регулировать введением добавок оксида алюминия [7]

Цель настоящей работы - исследование влияния химического состава системы $\mathrm{SO}_{4}^{2-}$ / $\mathrm{ZrO}_{2}-\mathrm{Al}_{2} \mathrm{O}_{3}$ и температуры ее формирования на фразовый состав, текстурные характерис- 
тики, кислотность и каталитические свойства в реакции алкилирования изобутана бутенами.

\section{ЭКСПЕРИМЕНТАЛЬНАЯ ЧАСТЬ}

Гидрат диоксида циркония получали “обратным" осаждением из раствора нитрата цирконила с концентрацией 220 г/л (в пересчете на $\mathrm{ZrO}_{2}$ ) раствором аммиака (66 г/л), конечное $\mathrm{pH}$ осаждения равно 10, молярное соотношение $\mathrm{NH}_{3} / \mathrm{ZrO}_{2}=4: 1$. Готовый осадок подвергали старению в течение 1 ч, затем отмывали до нейтрального значения $\mathrm{pH}$ промывных вод. Для введения сульфат-анионов осадок обрабатывали $16 \%$ раствором серной кислоты при массовом соотношении $\mathrm{ZrO}_{2} /$ $\mathrm{H}_{2} \mathrm{SO}_{4}$, равном 9 .

Оксид алюминия в состав катализаторов вводили посредством смешения сульфатированного гидрата оксида циркония с псевдобемитом промышленного производства (ЗАО “Промышленные катализаторы”, Рязань). Номинальное содержание $\mathrm{Al}_{2} \mathrm{O}_{3}$ в образцах составляло 20, 30, 50 мас. \% в расчете на полученный катализатор состава $\mathrm{SO}_{4}^{2-}-\mathrm{ZrO}_{2}-\mathrm{Al}_{2} \mathrm{O}_{3}$. Далее смеси сушили при $120^{\circ} \mathrm{C}$, а затем прокаливали в муфельной печи при температурах 550-700 ${ }^{\circ} \mathrm{C}$.

Полученным катализаторам различного химического состава присвоена номенклатуpa: ${ }^{m} \mathrm{SZA}_{k}$, где $k$ - номинальное содержание $\mathrm{Al}_{2} \mathrm{O}_{3}$ в катализаторе, мас. \%; $m$ - температура прокаливания образцов, ${ }^{\circ} \mathrm{C}$ (табл. 1 ). Для систем, в обозначении которых отсутствует показатель $m$, температурная обработка проводилась при $650{ }^{\circ} \mathrm{C}$. Образец чистого ди- оксида циркония, прокаленный при $650{ }^{\circ} \mathrm{C}$ и полученный без добавления оксида алюминия, обозначен как SZ. Чистый оксид алюминия, прокаленный при $650{ }^{\circ} \mathrm{C}$, а также его гидроксидный предшественник обозначены символом А.

Термогравиметрический анализ гидроксидных предшественников катализаторов (после сушки при $120{ }^{\circ} \mathrm{C}$ ) проводили с использованием прибора STA 449 C (Netzsch) в потоке газовой смеси состава 20 об. \% $\mathrm{O}_{2}+80$ об. \% $\mathrm{Ar}$ (чистота $99.999 \%$ ) в интервале температур 25-950 ${ }^{\circ} \mathrm{C}$ при скорости нагрева $10{ }^{\circ} \mathrm{C} /$ мин.

Удельную поверхность образцов $S_{\text {уд }}$ определяли методом низкотемпературной $(77.4 \mathrm{~K})$ адсорбции азота на приборе ASAP 2020M (Micromeritics). Величина $S_{\text {уд }}$ оценивалась методом БЭТ по изотерме адсорбции в интервале равновесных относительных значений паров азота $0.05-0.25$.

Рентгенофазовый анализ проводили с помощью порошкового дифрактометра D8 Advance Bruker в $\mathrm{CuK}_{\alpha}$-излучении с $\mathrm{Ni} \beta$ орильтром в области углов $2 \theta=20-75^{\circ}$ с шагом сканирования $0.1^{\circ}$ и временем накопления 3 с в каждой точке при $T=298 \mathrm{~K}$.

ИК-спектры адсорбированного СО регистрировались на приборе IR Prestige-21 фирмы Shimadzu при комнатной температуре и давлении в 5 торр с разрешением $4 \mathrm{~cm}^{-1}$ и числом накопления спектров 50. Перед анализом катализаторы прессовались в таблетки без связующего материала плотностью 20-30 мг/ $\mathrm{cm}^{2}$, переносились в ИК-ячейку с окнами из $\mathrm{CaF}_{2}$ и тренировались при температуре $400{ }^{\circ} \mathrm{C}$ в течение 2 ч под вакуумом. Остаточное давление не превышало $10^{-4}$ мбар.

ТАБЛИЦА 1

Химический состав и текстурные характеристики катализаторов

\begin{tabular}{|c|c|c|c|c|c|}
\hline \multirow[t]{2}{*}{ Образцы } & \multicolumn{3}{|c|}{ Номинальный состав катализатора, мас. \% } & \multirow{2}{*}{$\begin{array}{l}\text { Температура } \\
\text { прокаливания, }{ }^{\circ} \mathrm{C}\end{array}$} & \multirow{2}{*}{$\begin{array}{l}S_{\text {уд }}, \mathrm{m}^{2} / \Gamma \\
\mathrm{m}^{2} / \Gamma\end{array}$} \\
\hline & $\mathrm{SO}_{4}^{2-}$ & $\mathrm{ZrO}_{2}$ & $\mathrm{Al}_{2} \mathrm{O}_{3}$ & & \\
\hline $\mathrm{SZ}$ & 10 & 90 & 0 & 650 & 110 \\
\hline $\mathrm{SZA}_{20}$ & 8 & 72 & 20 & 650 & 155 \\
\hline $\mathrm{SZA}_{30}$ & 7 & 63 & 30 & 650 & 172 \\
\hline $\mathrm{SZA}_{50}$ & 5 & 45 & 50 & 650 & 188 \\
\hline A & 0 & 0 & 100 & 650 & 209 \\
\hline${ }^{550} \mathrm{SZA}_{20}$ & 8 & 72 & 20 & 550 & 118 \\
\hline${ }^{600} \mathrm{SZA}_{20}$ & 8 & 72 & 20 & 600 & 119 \\
\hline${ }^{700} \mathrm{SZA}_{20}$ & 8 & 72 & 20 & 700 & 115 \\
\hline
\end{tabular}


ТАБЛИЦА 2

Углеводородный состав сырья для реакции алкилирования изобутана бутенами

\begin{tabular}{lcr}
\hline Компоненты & \multicolumn{2}{c}{ Содержание, мас. \% } \\
\cline { 2 - 3 } & ИБФ & ББФ \\
\hline Пропан & 0.02 & 0.49 \\
Изобутан & 99.41 & 36.63 \\
1-Бутилен & 0.36 & 28.67 \\
н-Бутан & 0.06 & 8.50 \\
2-Транс-бутен & 0.09 & 15.17 \\
2-Цис-бутен & 0.06 & 10.48 \\
C $_{5+}$ & 0.00 & 0.06 \\
\hline
\end{tabular}

Испытания катализаторов в процессе алкилирования изобутана бутенами проводились в автоклаве из нержавеющей стали вместимостью 180 мл с перемешиванием. В качестве сырья использовали изобутановую (ИБФ) и бутан-бутеновую (ББФ) фрракции (табл. 2.). В автоклав загружали 40 г ИБФ и 4 г катализатора с размером гранул 0.25-1.0 мм, ББФ подавали в автоклав в ходе процесса из расчета 0.20-0.22 г бутенов на 1 г катализатора в час. Все испытания проводились при температуре $40{ }^{\circ} \mathrm{C}$, давлении $2.0 \mathrm{MПа} \mathrm{и} \mathrm{продолжи-}$ тельности эксперимента 1 ч. Продукты анализировали методом газожидкостной хроматографрии на приборе “Хромос ГХ-1000”, оснащенном капиллярной колонкой HP Pona длиной 100 м и пламенно-ионизационным детектором. Состав продуктов определяли методом нормализации.

Степень превращения бутенов $X$ (в \%) и выход продуктов $\mathrm{C}_{5+}$ (алкилата) на превращенные бутены $\mathrm{Y}_{\mathrm{C} 5+}($ в г/г) рассчитывали по следующим формулам:

$$
\begin{aligned}
X & =100\left[1-W_{\mathrm{C}_{4}}^{\text {пр }}\left(M_{\text {ИБФ }}+M_{\text {ББФ }}\right) /\left(W_{\mathrm{C}_{4}}^{\text {ИБФ }} M_{\text {ИБФ }}\right.\right. \\
& \left.\left.+W_{\mathrm{C}_{4}}^{\text {ББФ }} M_{\text {ББФ }}\right)\right]
\end{aligned}
$$

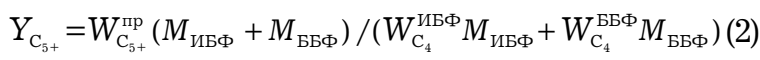
где $W_{\mathrm{C}_{4}}^{\text {пр }}, W_{\mathrm{C}_{4}}^{\text {ИБФ }}$ и $W_{\mathrm{C}_{4}}^{\text {ББФ }}$ - массовая доля бутенов в продуктах, а также в исходных ИБФ и ББФ соответственно; $M_{\text {ИБФ }}$ и $M_{\text {ББФ }}-$ массы ИБФ и ББФ, поданных в автоклав к моменту анализа соответственно; $W_{\mathrm{C}_{5+}}^{\text {пр }}-$ суммарная массовая доля жидких продуктов алкилирования.

\section{РЕЗУЛЬТАТЫ И ОБСУЖДЕНИЕ}

В табл. 1 приведены данные по удельной поверхности для образцов $\mathrm{SO}_{4}^{2-}-\mathrm{ZrO}_{2}-\mathrm{Al}_{2} \mathrm{O}_{3}$. Видно, что с ростом содержания оксида алюминия удельная поверхность закономерно возрастает от $110 \mathrm{~m}^{2} /$ г для $\mathrm{SZ}$ до $188 \mathrm{~m}^{2} /$ г для образца, содержащего $50 \% \mathrm{Al}_{2} \mathrm{O}_{3}$. При этом температура прокаливания существенно не влияет на текстуру образцов, и ее повышение с 550 до $700{ }^{\circ} \mathrm{C}$ для образца с 20 мас.\% $\mathrm{Al}_{2} \mathrm{O}_{3}$ приводит к снижению величины $S_{\text {уд }}$ лишь с 118 до $115 \mathrm{~m}^{2} /$ г.

На рис. 1 приведены результаты термогравиметрического анализа полученных образцов сульфатированного гидрата диоксида циркония с добавками гидроксида алюминия и без них. Для сравнения здесь же приведена кривая ДТГ псевдобемита (кривая А). Потеря массы всех образцов в области температур до $200{ }^{\circ} \mathrm{C}$ обусловлена удалением фризически адсорбированной воды. Потеря массы в области температур $200-400{ }^{\circ} \mathrm{C}$ для образца $\mathrm{SZ}$ связана с удалением химически связанной воды и кристаллизацией образца. Сигнал на кривой ДТГ в области $667-850{ }^{\circ} \mathrm{C}$ обусловлен удалением серы в виде оксидов.

На кривой ДТГ псевдобемита (см. рис. 1) присутствуют характерные пики при 276 и 421-423 ${ }^{\circ} \mathrm{C}$, обусловленные дегидратацией

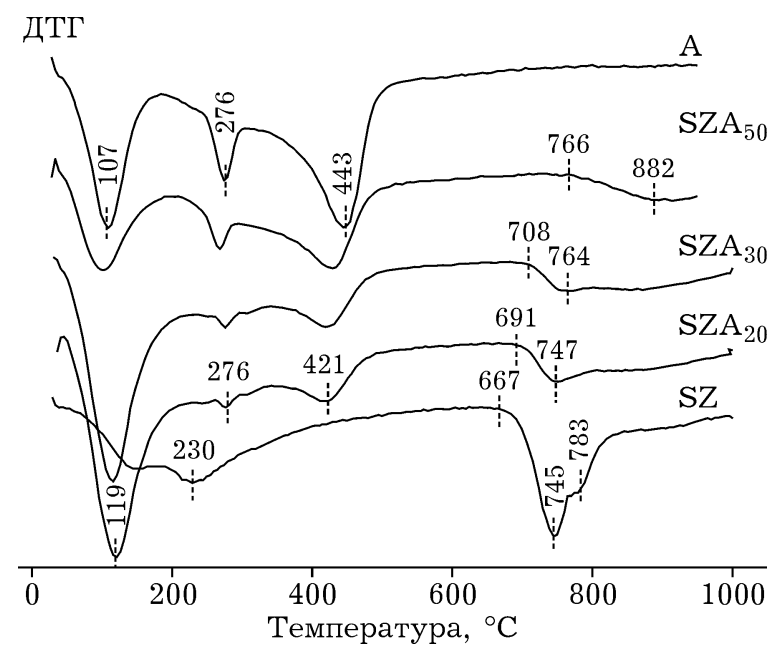

Рис. 1. Влияние содержания добавки оксида алюминия на процесс формирования системы $\mathrm{SO}_{4}^{2-}-\mathrm{ZrO}_{2}-\mathrm{Al}_{2} \mathrm{O}_{3}$ из гидроксидных предшественников. 
псевдобемита и образованием $\gamma$-оксида алюминия. Для образцов SZA вид дифореренциальных кривых потерь массы до $550{ }^{\circ} \mathrm{C}$ в основном определяется суперпозицией пиков исходных компонентов и зависит от их соотношения в смеси. При этом введение оксида алюминия принципиально влияет на характер удаления оксидов серы из образцов. Уже при добавлении 20 мас. \% $\mathrm{Al}_{2} \mathrm{O}_{3}$ пик, соответствующий удалению $\mathrm{SO}_{x}$, сильно размывается, достигая предельной температуры проведения анализа $\left(950{ }^{\circ} \mathrm{C}\right)$. При дальнейшем повышении содержания оксида алюминия он смещается в область более высоких температур (от 667 до $776^{\circ} \mathrm{C}$ ). Исходя из этого мож-
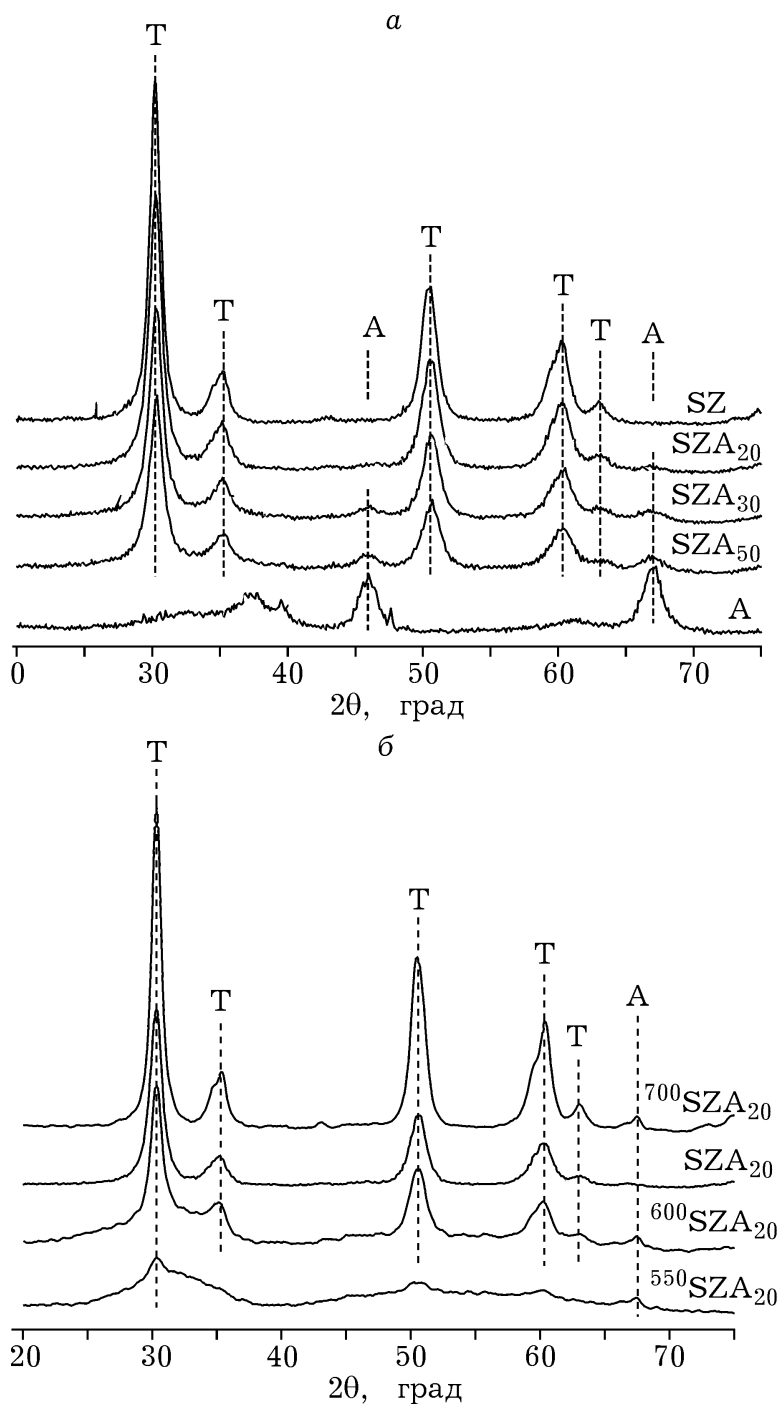

Рис. 2. Влияние содержания добавки оксида алюминия (a) и температуры прокаливания (б) систем $\mathrm{SO}_{4}^{2-}-\mathrm{ZrO}_{2}-$ $\mathrm{Al}_{2} \mathrm{O}_{3}$ на их фазовый состав. $\mathrm{T}$ - тетрагональная фраза $\mathrm{ZrO}_{2}, \mathrm{~A}-$ фраза $\gamma-\mathrm{Al}_{2} \mathrm{O}_{3}$. но заключить, что введение в катализатор оксида алюминия позволяет уменьшить потери серы при прокаливании благодаря прочному связыванию сульфат-анионов с поверхностью оксида алюминия.

Согласно данным рентгенофразового анализа, на дифрактограмме образца SZ с температурой прокаливания $650{ }^{\circ} \mathrm{C}$ (рис. $\left.2, a\right)$ идентифицируется только фаза тетрагонального $\mathrm{ZrO}_{2}$. Для образцов $\mathrm{SO}_{4}^{2-}-\mathrm{ZrO}_{2}-\mathrm{Al}_{2} \mathrm{O}_{3}$, наряду с пиками тетрагонального $\mathrm{ZrO}_{2}$, проявляются типичные для фразы $\gamma-\mathrm{Al}_{2} \mathrm{O}_{3}$ рефлексы, интенсивность которых возрастает с повышением содержания оксида алюминия в составе катализаторов. Температура прокаливания
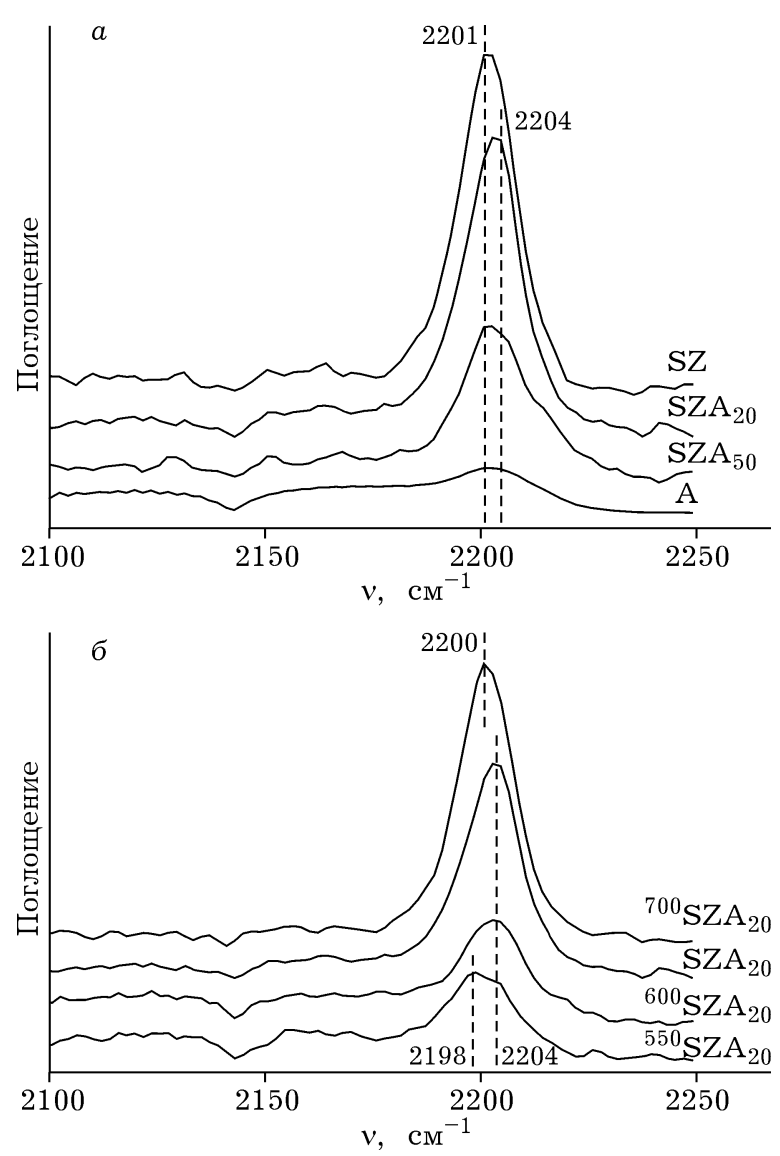

Рис. 3. ИК-спектры адсорбированного СО образцов $\mathrm{SO}_{4}^{2-}-$ $\mathrm{ZrO}_{2}-\mathrm{Al}_{2} \mathrm{O}_{3}$ с различным содержанием оксида алюминия (a) и прокаленных при различных температурах (б). 
оказывает существенное влияние на формирование фразы тетрагонального $\mathrm{ZrO}_{2}$ (см. рис. 2, б). Судя по характерным гало на дифрактограммах, при $550{ }^{\circ} \mathrm{C}$ формируются плохо окристаллизованные образцы, содержащие наряду с тетрагональным $\mathrm{ZrO}_{2}$ большое количество рентгеноаморфной фразы. Сужение рефлексов на дифрактограммах (см. рис. 2, б) и возрастание их интенсивности с ростом температуры прокаливания указывает на повышение доли кристаллической фразы и увеличение размеров кристаллитов.

Изучение кислотных свойств образцов $\mathrm{SO}_{4}^{2-} / \mathrm{ZrO}_{2}-\mathrm{Al}_{2} \mathrm{O}_{3}$ методом ИК-спектроскопии адсорбированного СО показало наличие на поверхности катализаторов ЛКЦ (льюисовских кислотных центров) средней силы (п. п. адсор-
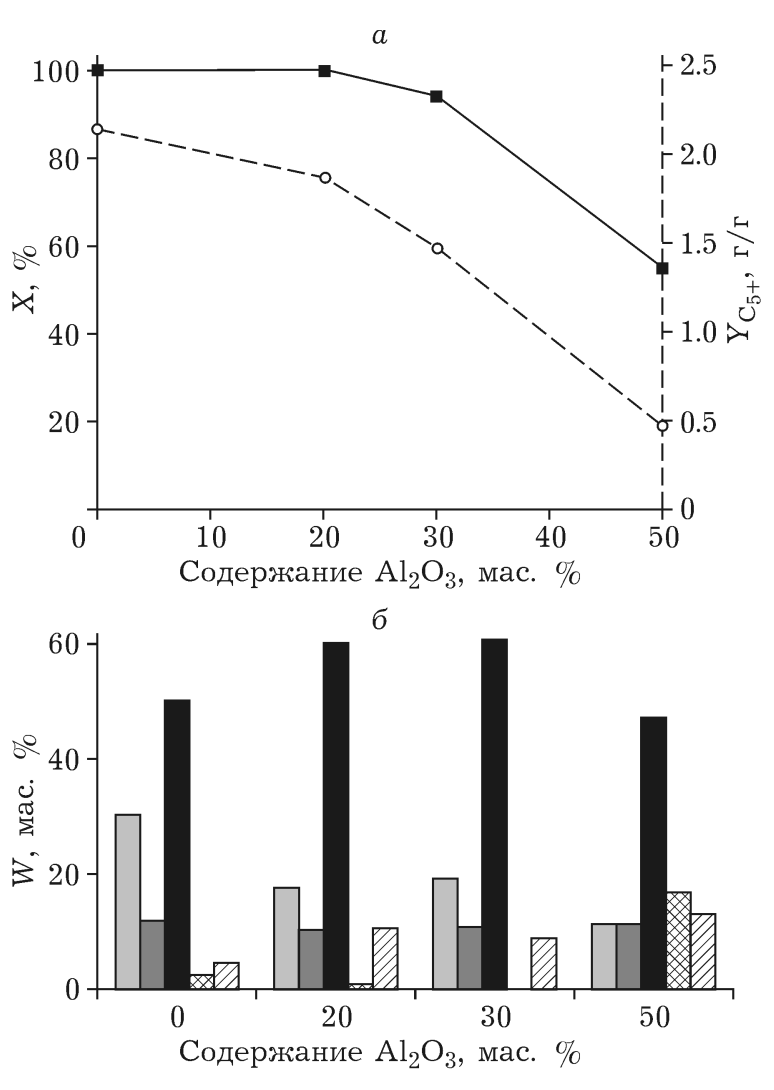

$\square 1$

$3 \otimes 4$

D 5

Рис. 4. Влияние содержания добавки оксида алюминия в системе $\mathrm{SO}_{4}^{2-}-\mathrm{ZrO}_{2}-\mathrm{Al}_{2} \mathrm{O}_{3}$ на показатели процесса алкилирования: $a$ - степень превращения бутенов $X$ и выход углеводородов $\mathrm{C}_{5+} \mathrm{Y}_{\mathrm{C5}} ;$; 6 - состав жидких продуктов $W$. $1-\mathrm{C}_{5}-\mathrm{C}_{7}, 2-$ ДМГ, 3 - ТМП, 4 - другие $\mathrm{C}_{8}, 5-\mathrm{C}_{9+}$ бированного СО в пределах 2201-2204 $\mathrm{cm}^{-1}$ ). Увеличение содержания $\mathrm{Al}_{2} \mathrm{O}_{3}$ в образцах приводит к снижению количества кислотных центров, о чем свидетельствует снижение интенсивности данных полос поглощения (рис. 3, a). Скорее всего, это связано с более низкой собственной кислотностью оксида алюминия (см. рис. 3, a, кривая А). С ростом температуры прокаливания интенсивность полос поглощения для образца $\mathrm{SZA}_{20}$ возрастает, что указывает на увеличение количества кислотных центров (см. рис. 3, б).

Испытания серии образцов с различным содержанием оксида алюминия показали (рис. 4), что полное превращение бутенов наблюдается лишь при содержании $\mathrm{Al}_{2} \mathrm{O}_{3} 20$ мас. \% и менее. Так, в случае SZ выход продуктов $\mathrm{C}_{5+}$ на превращенные бутены $\mathrm{Y}_{\mathrm{C}_{5+}}>2$,
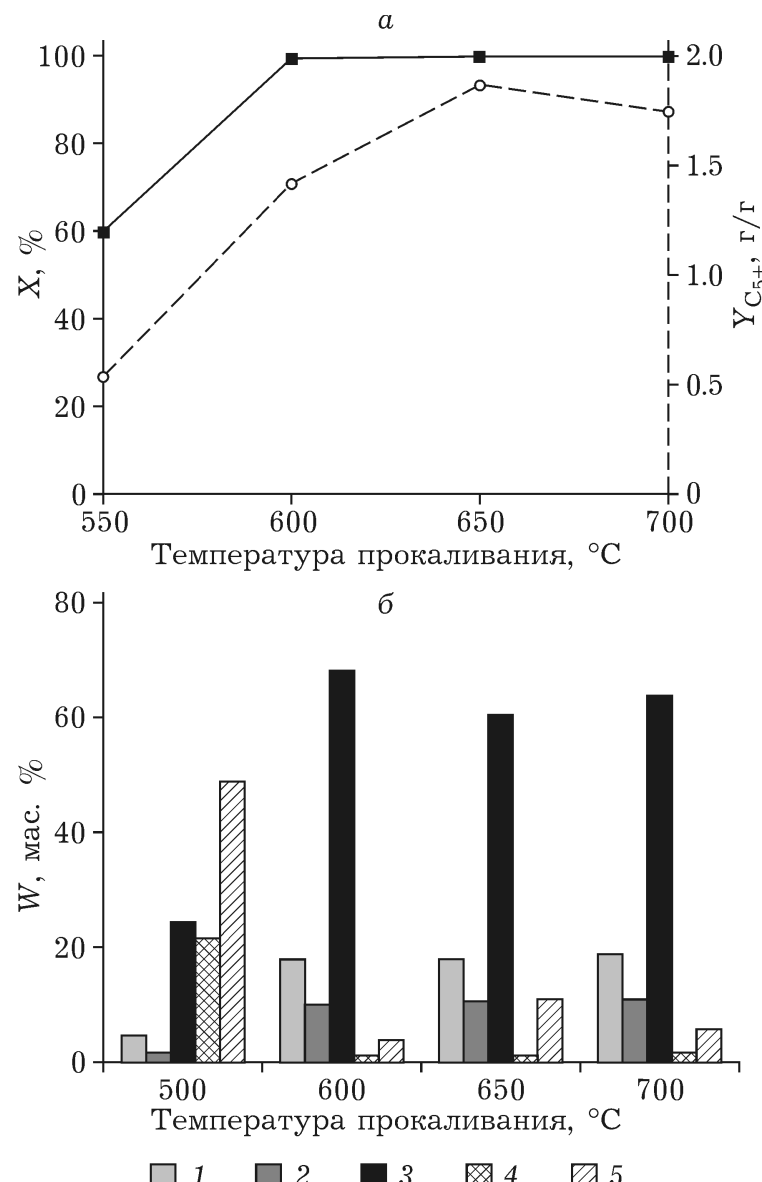

Рис. 5. Влияние температуры прокаливания системы $\mathrm{SO}_{4}^{2-}-$ $\mathrm{ZrO}_{2}-\mathrm{Al}_{2} \mathrm{O}_{3}$ на показатели процесса алкилирования: $a$ - степень превращения бутенов $X$ и выход углеводородов $\mathrm{C}_{5+}\left(\mathrm{Y}_{\mathrm{C} 5+}\right) ; \sigma-$ состав жидких продуктов $W$. $1-\mathrm{C}_{5}-\mathrm{C}_{7}, 2-$ ДМГ, 3 - ТМП, 4 - другие $\mathrm{C}_{8}, 5-\mathrm{C}_{9+}$. 
что характерно для катализаторов, обладающих высокой кислотностью поверхности. Высокий выход обусловлен тем, что в системе, наряду с алкилированием изобутана бутенами, протекает реакция самоалкилирования изобутана. При этом состав продуктов алкилирования на образце SZ отличается невысоким содержанием целевых триметилпентанов (не более 50 мас. \%) и значительной (почти 30 мас. \%) долей углеводородов $\mathrm{C}_{5}-\mathrm{C}_{7}$, что указывает на высокую активность данного катализатора в реакциях крекинга. Образец $\mathrm{SZA}_{20}$, который, по данным ИКС адсорбированного $\mathrm{CO}$, обладает меньшей по сравнению с SZ кислотностью (см. рис. 3, a), обеспечивает выход углеводородов $\mathrm{C}_{5+}$ на превращенные бутены на уровне 1.9. При этом содержание ТМП в продуктах алкилирования на катализаторе $\mathrm{SZA}_{20}$ превышает 60 мас. \%, а доля продуктов крекинга меньше 20 мас. \%. Дальнейшее повышение содержания $\mathrm{Al}_{2} \mathrm{O}_{3}$ и соответствующее ему уменьшение кислотности поверхности образцов приводит к значительному снижению активности катализаторов. Так, системы $\mathrm{SZA}_{30}$ и $\mathrm{SZA}_{50}$ уже не обеспечивают полного превращения бутенов ( $X=95$ и 56 \% соответственно), а низкий выход алкилата на них указывает на принципиально иной характер реакций, протекающих в системе. И если для $\mathrm{SZA}_{30}$, который обеспечивает выход $\mathrm{C}_{5+}$ на уровне 1.5, можно говорить о протекании, наряду с алкилированием, реакций олигомеризации бутенов, то на $\mathrm{SZA}_{50}$, судя по выходу алкилата ( 0.5) и составу продуктов, в реакциях превращения бутенов преобладают олигомеризация и сопряженная олигомеризация. Таким образом, оптимальной кислотностью для процесса алкилирования характеризуется образец с содержанием $\mathrm{Al}_{2} \mathrm{O}_{3} 20$ мас. \%. Он обеспечивает высокий выход алкилата и максимальное содержание в нем целевых продуктов - ТМП.

Исследование влияния температуры прокаливания на каталитические свойства образцов $\mathrm{SZA}_{20}$ показало (рис. 5), что для достижения полного превращения бутенов образ- цы необходимо прокаливать при температуре от $600{ }^{\circ} \mathrm{C}$ и выше. Так, образцы, прокаленные при 600-700 ${ }^{\circ} \mathrm{C}$, обеспечивают близкое содержание ТМП в жидких продуктах алкилирования $\left(\mathrm{C}_{5+}\right)$, однако максимальный выход последних составляет 1.9 г/г и достигается на образце, прокаленном при $650{ }^{\circ} \mathrm{C}$.

\section{ЗАКЛЮЧЕНИЕ}

Показано, что введение добавок оксида алюминия в SZ позволяет значительно изменять его текстуру и кислотные свойства, а также препятствует уносу серы. Лучшие свойства систем SZA в качестве катализаторов алкилирования изобутана бутенами обеспечиваются при введении $\mathrm{Al}_{2} \mathrm{O}_{3}$ в количестве 20 мас. \%. Модификатор в таких количествах практически не снижает активности катализатора, но обеспечивает более высокий выход триметилпентанов и уменьшает интенсивность протекания побочных реакций крекинга.

Установлено, что с повышением температуры прокаливания возрастает степень кристалличности и кислотность образцов сульфатированного диоксида циркония с добавкой оксида алюминия. Показано, что оптимальная температура прокаливания для катализатора алкилирования равна $650{ }^{\circ} \mathrm{C}$.

\section{СПИСОК ЛИТЕРАТУРЫ}

1 Хаджиев С. Н., Капустин В. М., Максимов А. Л., Чернышева Е. А., Кадиев Х. М., Герзелиев И. М., Колесниченко Н. В. // Нефтепереработка и нефтехимия. 2014. № 9. C. 3-10.

2 Хаджиев С. Н., Герзелиев И. М. // Хим. журн. 2010. № 3. C. 50-53.

3 Касимов А. А., Пириева Х. Б., Азизов А. Г., Гаджизаде С. М., Джамалова С. А., Зейналова С. Х. // Нефтепереработка и нефтехимия. 2014. № 3. С. 7-12.

4 Weitkamp J., Traa Y. // Handbook of Heterogeneous Catalysis. 1997. Vol. 4, No. 9. P. 2039-2065.

5 Feller A., Zuazo I., Guzman A., Barth J.O., Lercher J. A. // J. Catal. 2003. Vol. 216, No. 1-2. P. 313-323.

6 Wanga Z., Shuia H., Zhua Y., Gaob J. // Fuel. 2009. Vol. 88, No. 5. P. 885-889.

7 Zalewski D. J., Alerasool S., Doolin P. K. // Catal. Today. 1999. Vol. 53. P. 419-432. 